\title{
Thermally activated deformation of nanocrystalline and coarse grained CoCrFeNiMn high entropy alloy in the temperature range $4.2-350 \mathrm{~K}$
}

\author{
A.V. Podolskiy ${ }^{1}$, E. Schafler ${ }^{2}$, E.D. Tabachnikova ${ }^{1}$, \\ M.A. Tikhonovsky ${ }^{3}$, and M.J. Zehetbauer ${ }^{2}$ \\ ${ }^{1}$ B. Verkin Institute for Low Temperature Physics and Engineering \\ 47 Nauky Ave., Kharkiv 61103, Ukraine \\ E-mail: podolskiy@ilt.kharkov.ua \\ ${ }^{2}$ Physics of Nanostructured Materials, Faculty of Physics, University of Vienna \\ Boltzmanngasse 5, A-1090 Wien, Austria \\ ${ }^{3}$ National Science Center, Kharkov Institute of Physics and Technology \\ 1 Akademicheskaya Str., Kharkiv 61108, Ukraine
}

Received April 16, 2018, published online July 26, 2018

\begin{abstract}
Mechanical properties of a nanocrystalline $(\sim 60 \mathrm{~nm})$ and a coarse grained (grain sizes $\sim 4 \mu \mathrm{m})$ CoCrFeNiMn high entropy alloys were studied in uniaxial compression in the temperature range 4.2-350 K. Temperature dependences of yield strength, flow stress and strain rate sensitivity have been registered and analyzed in the framework of two thermal activation deformation models, that of thermal activation of local barrier overcoming, and that of Peierls valley double kink formation. Microscopic parameters of dislocation interaction with the barriers for thermally activated motion are estimated and low temperature deformation mechanisms are discussed.
\end{abstract}

Keywords: high entropy alloy, nanocrystalline, low temperature, dislocation, thermal activation analysis.

\section{Introduction}

The high entropy alloys (HEAs) are new and intriguing materials [1-4], which have unique mechanical properties such as a combination of high strength and good plasticity, high fracture toughness in a wide range of low temperatures, high thermal stability, and others. These properties are related to the multicomponent structure of the alloys and distorted crystal lattice due to presence of elements with different atomic radius. At present, the most prominent HEA is CoCrFeNiMn, which has a single fcc phase and high plasticity at all temperatures, including cryogenic ones [4-7]. The carriers of plasticity are reliably found in a wide range of temperatures [5,6]. The principles of the thermally activated plastic deformation of coarse grained CoCrFeNiMn alloy, which govern the temperature dependences of strength and strain rate sensitivity at low homologous temperatures, were attempted to study in several works [8-10], but they were not sufficiently clarified (mainly due to absence of the detailed temperature de- pendence of yield stress and strain rate sensitivity), which therefore will be the main task of this work.

The nanocrystalline state of the CoCrFeNiMn alloy achieved by high pressure torsion (HPT) at a processing temperature $300 \mathrm{~K}$, demonstrates both an outstanding strength and at the same time good plasticity [11,12], while the deformation mechanisms behind still are not clear so far. Therefore, the mechanical properties of the coarse grained (CG) and nanocrystalline (NC) CoCrFeNiMn HEA will be studied and compared in a broad range of low temperatures; a careful thermal activation analysis of the experimental data should allow to clarify the microscopic mechanisms of the thermally activated plastic deformation of both structural states of CoCrFeNiMn in question.

\section{Materials and methods}

Ingots of the equiatomic fcc CoCrFeNiMn high entropy alloy were produced by arc melting of the components in high-purity argon inside a water-cooled copper cavity. The purities of the alloying elements were higher than $99.9 \%$. 
To ensure chemical homogeneity, the ingots were flipped over and re-melted at least 5 times. After that, the homogenization annealing was carried out at $1000^{\circ} \mathrm{C}$ for $24 \mathrm{~h}$ (in vacuum), which was followed by rolling from 5.3 to $2 \mathrm{~mm}$, annealing at $800^{\circ} \mathrm{C}(1 \mathrm{~h})$, rolling from 2 to $1 \mathrm{~mm}$, annealing at $800^{\circ} \mathrm{C}(1 \mathrm{~h})$. The average grain size after such treatment was $4 \mu \mathrm{m}$.

Severe plastic straining of the alloy was performed by the High Pressure Torsion (HPT) method. Disc-shaped billets with diameter $10 \mathrm{~mm}$ and thickness $0.9 \mathrm{~mm}$ were processed by 5 rotations of HPT at a hydrostatic pressure of $6 \mathrm{GPa}$ and temperature $300 \mathrm{~K}$. Plungers have been rotated by a speed of $0.2 \mathrm{rot} / \mathrm{min}$. It is known that such HPT regime allows to produce uniform NC structural state with average grain sizes 50-60 nm [11,12].

Compression samples with the shape of rectangular prisms $0.8 \times 0.8 \times 1.3 \mathrm{~mm}$, were cut from the HPT discs. CG compression samples with the same dimensions were cut from the initial discs.

The mechanical characteristics of HPT processed as well as of CG CoCrFeNiMn samples were studied in a MRK-3 deformation machine at initial strain rate $3 \cdot 10^{-4} \mathrm{~s}^{-1}$. Cryogenic temperatures were achieved by liquid nitrogen and helium and temperatures above $290 \mathrm{~K}$ were achieved by hot air.

During the measurement of the deformation curves, the shear flow stress sensitivity $\Delta \tau / \Delta \ln \dot{\varepsilon}$ was estimated from the change in the flow stress by increasing the rate of deformation by a factor of 9 . The resolved shear stress $\tau$ was expressed by the relation $\tau=\sigma / 3$ typical for texture free fcc polycrystalline materials [13].

The values of apparent activation volume for the process of plastic deformation were calculated from the rate sensitivity of yield stress [14]

$$
V(T)=k T \frac{\Delta \ln \dot{\varepsilon}}{\Delta \tau(T)}
$$

where $k$ is the Boltzmann constant.

For the thermal activation analysis of the NC and CG structural states, the temperature dependences of the shear flow stress $\tau(T)$ and of the strain rate sensitivity $\Delta \tau / \Delta \ln \dot{\varepsilon}(T)$ are required, which have been registered at the stage of well developed plastic strain, but very close to the yield limit to reduce influence of strain hardening at different temperatures: in this work the values at $1 \%$ of plastic strain are analyzed. In NC state the strain rate sensitivity was registered within a temperature range of $65-350 \mathrm{~K}$, as relatively low plasticity below $65 \mathrm{~K}$ does not allow to reliably determine the $\Delta \tau / \Delta \ln \dot{\varepsilon}$ values.

\section{Experimental results}

The temperature dependences of the yield strength $\sigma_{0.2}$ of the HPT deformed NC and initial CG CoCrFeNiMn high entropy alloy can be seen in Fig. 1 .

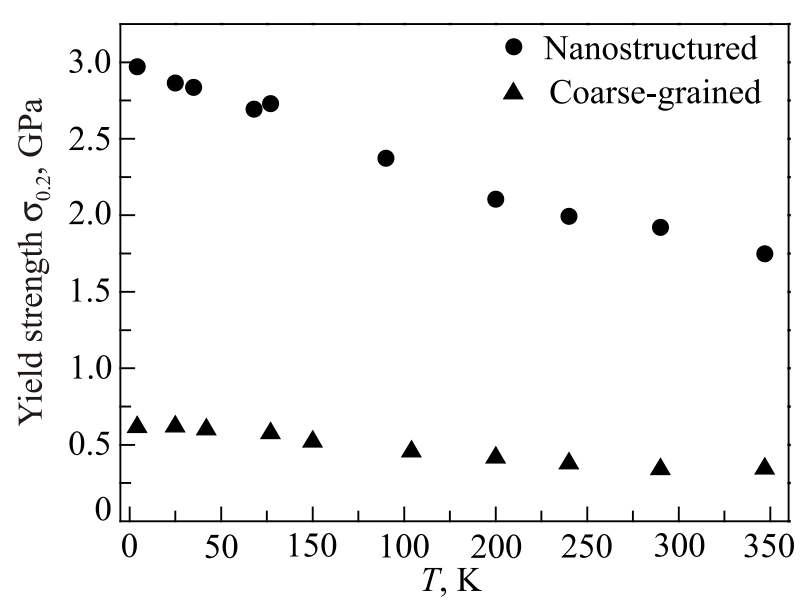

Fig. 1. Temperature dependence of yield strength $\sigma_{0.2}$ in compression of nanocrystalline (grain size $\sim 60 \mathrm{~nm}$ ) and initial coarse grained (grain size $\sim 4 \mu \mathrm{m}$ ) CoCrFeNiMn high entropy alloy.

The strength of CG CoCrFeNiMn (Fig. 1) well combines with the literature data for the tension of the samples with comparable grain sizes $(\sim 5 \mu \mathrm{m})[6]$ and $(\sim 17 \mu \mathrm{m})$ [10]. The comparison of yield strength at different compression temperatures shown in Fig. 1 demonstrates that decrease of grain size from $4 \mu \mathrm{m}$ to approximately $60 \mathrm{~nm}$ leads to significant (5-6 times) increase of strength. The value of the yield strength at $300 \mathrm{~K}$ in tension (1.95 GPa) of HPT CoCrFeNiMn [11] is in good correlation with the value of yield strength in compression (Fig. 1) - 2 GPa, so very weak SD effect (strength difference in tension and compression) is observed.

The plasticity of the NC CoCrFeNiMn in compression is rather high in a wide temperature range: approximately $10 \%$ at $350 \mathrm{~K}$, increasing up to $30 \%$ at $200 \mathrm{~K}$, decreasing to $10 \%$ at $77 \mathrm{~K}$ and approximately to $1 \%$ at $4.2 \mathrm{~K}$. At the temperature $4.2 \mathrm{~K}$, significantly serrated plastic deformation is registered in the CG and NC states, which can be explained by collective avalanche-type motion of dislocations [15].

The temperature dependences of the shear flow stress $\tau(T)$ and of the strain rate sensitivity $\Delta \tau / \Delta \ln \dot{\varepsilon}(T)$ have been determined at $1 \%$ of plastic strain and are shown in Fig. 2 $\left(\tau_{1}(T)\right)$ and Fig. $3(\Delta \tau / \Delta \ln \dot{\varepsilon}(T))$. A wide maximum is observed in the $\Delta \tau / \Delta \ln \dot{\varepsilon}(T)$ dependence at $150-250 \mathrm{~K}$ for NC state and at 100-200 K for CG state. Such "bell-shaped" temperature dependence of the strain rate sensitivity is typical of many metals with fcc, hcp and bcc crystal lattice.

From the flow stress sensitivity for strain value $1 \%$ (Fig. 3), the activation volume calculated according to relation (1), shown in Fig. 4 in $b^{3}$ units, where $b$ is Burgers vector, being for fcc structures, with $a=3.6 \AA$ [16] as the lattice parameter.

The activation volume of the CG CoCrFeNiMn high entropy alloy had been evaluated from strain rate change and stress relaxation tests in several works: $18 b^{3}$ (at $77 \mathrm{~K}$ ) and $85 b^{3}$ (at 293 K) [8]; $40 b^{3}$ (at $293 \mathrm{~K}$ ) [9]; $60 b^{3}$ at (77 K) and 

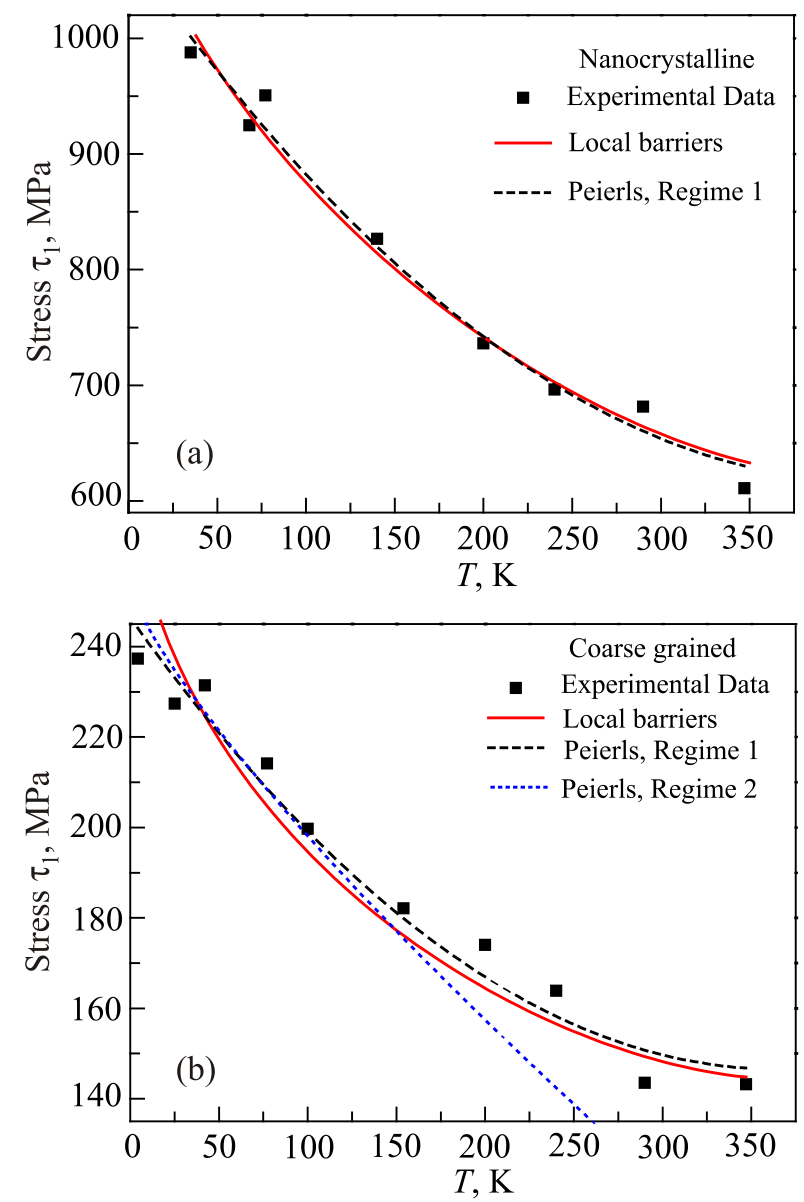

Fig. 2. (Color online) Temperature dependences of the shear stress $\tau_{1}$ (at $1 \%$ plastic strain) of the CoCrFeNiMn high entropy alloy in nanocrystalline (a) and coarse grained (b) states. The lines are theoretical dependences (see Sec. 4).

$340 b^{3}$ (at $293 \mathrm{~K}$ ) [10]. Large difference in values partly can be explained by difference in the used Taylor factor $(\sqrt{3}, 2$, 3), different grain sizes of the samples and the different type of experiments (strain rate jumps and relaxation), but nevertheless it should be noted that the observed variance of the activation volume values is much higher than variance of the corresponding strengths characteristics and maybe more fundamental reasons underline it.

The values and temperature dependence of the activation volume of the NC CoCrFeNiMn alloy in general are similar to those observed in NC fcc alloys [17].

\section{Analysis and discussion}

The microscopic mechanisms of plastic strain in CG fcc CoCrFeNiMn high entropy alloy have been discussed in $[5,6,18]$ in a wide range of low temperatures: the main deformation mechanism is typical of fcc materials sliding of full $\langle 110\rangle\{111\}$ dislocations; twinning is registered at $300 \mathrm{~K}$ and its activity is increasing with decrease of temperature $[6,18,19]$. It was found $[18,19]$ that twinning actively participates in the plastic deformation at later stages of the
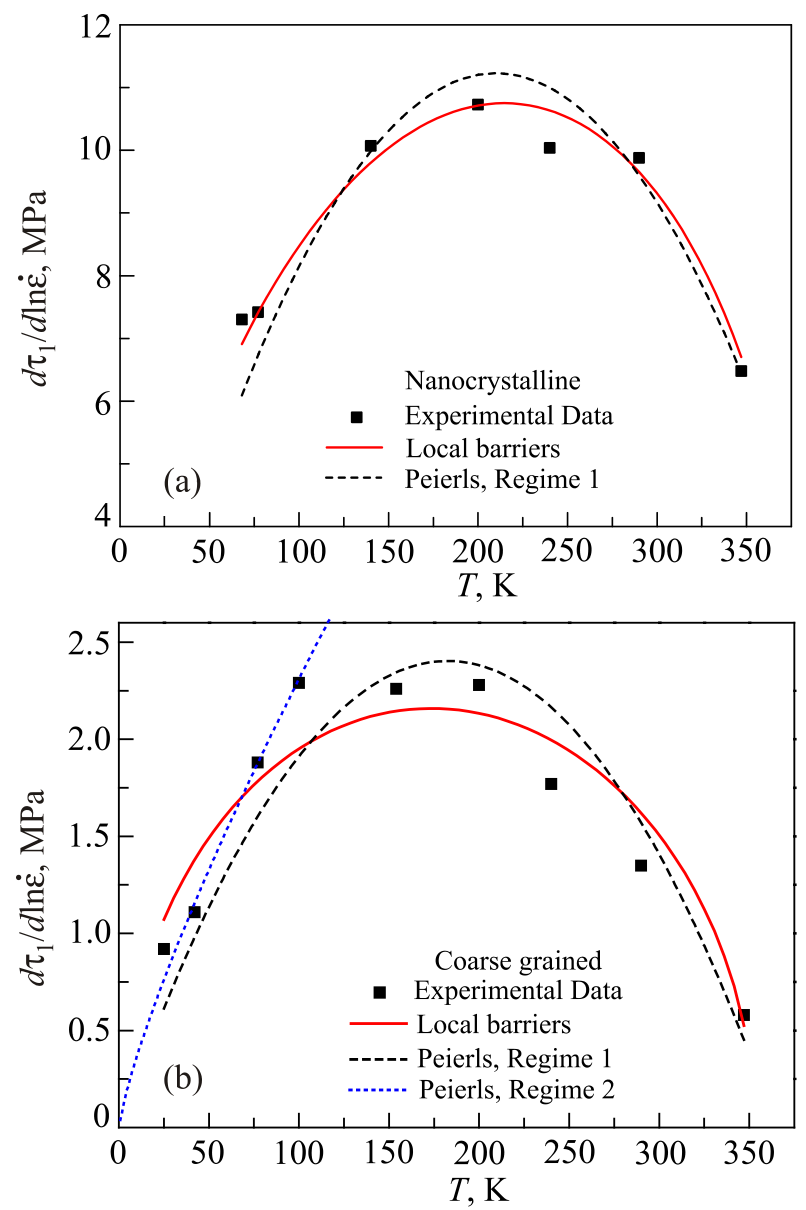

Fig. 3. (Color online) Temperature dependences of the strain rate sensitivity $\Delta \tau_{1} / \Delta \ln \dot{\varepsilon}$ (at $1 \%$ plastic strain) of the CoCrFeNiMn high entropy alloy in nanocrystalline (a) and coarse grained (b) states. The lines are theoretical dependences (see Sec. 4).

deformation curve (typically after 5\% of plastic strain). Thus it can be expected that only dislocation processes are responsible the experimental data (Figs. 2-4). Compression tests in the CoCrFeNiMn single crystal allowed to estimate the critical resolved shear stress (CRSS) for $<110>\{111\}$ dislocations at temperatures 300 and $77 \mathrm{~K}$ (70 and $175 \mathrm{MPa}$ correspondingly) [20]. These values cannot be directly compared to shear stress values of polycrystals (Fig. 2) due to different values of internal stresses, but the difference $\tau_{c r s s 77}-$ $\tau_{\text {crss } 300}==105 \mathrm{MPa}$ in the single crystal is roughly comparable to difference $\tau_{C G 77}-\tau_{C G 300}=71 \mathrm{MPa}$ of CG CoCrFeNiMn (Fig. 2(b)), indicating that the shear stress (Fig. 2(b)) can be considered as a stress acting at the full dislocation in its glide plane. In NC state, however, this difference is as large as $\tau_{N C 77}-\tau_{N C 300}=269 \mathrm{MPa}$, indicating that in this state the temperature dependence of strength cannot be explained by thermally activated motion of dislocations inside the grains.

The present CoCrFeNiMn alloy demonstrates a rather strong temperature dependence of the flow stress (Figs. 1, 2) in CG as well as in NC state (approximately 1.7-1.8 times 

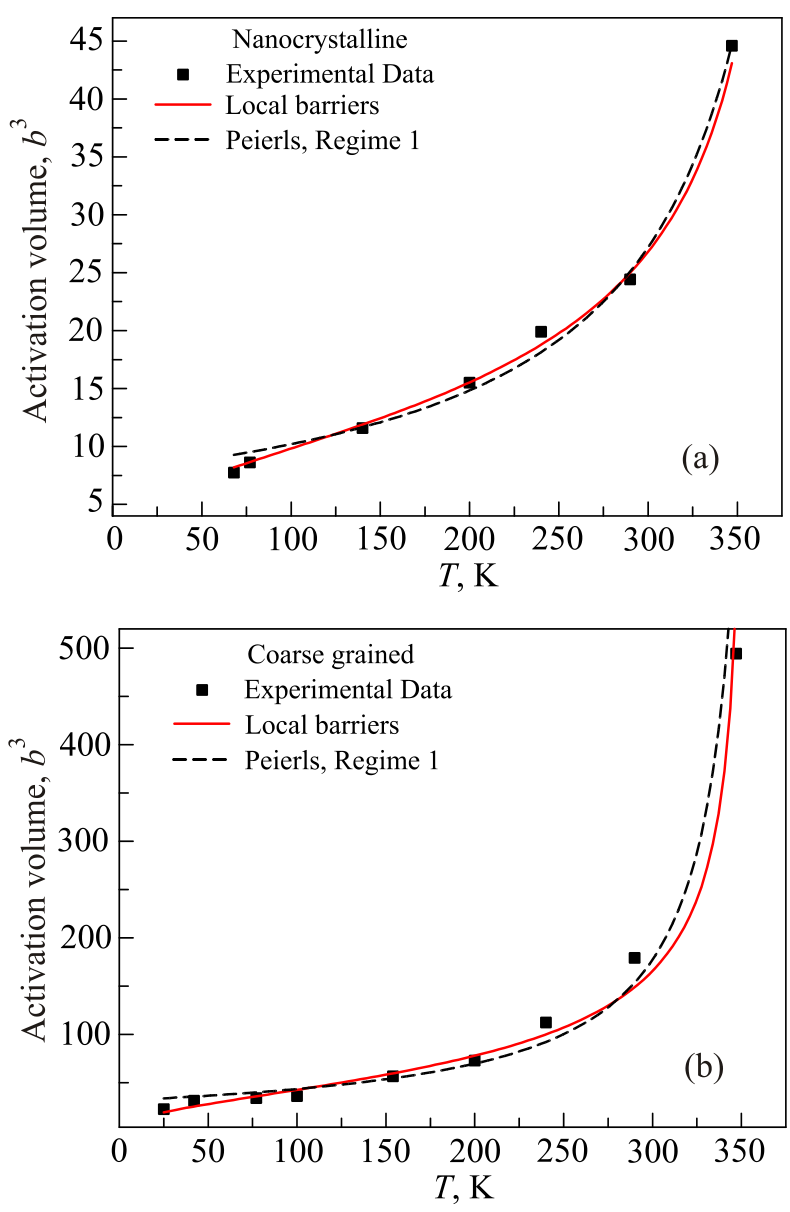

Fig. 4. Temperature dependences of the activation volume (measured at the value of plastic strain 1\%) of the CoCrFeNiMn high entropy alloy in nanocrystalline (a) and coarse grained (b) structural states. The lines are theoretical dependences (see Sec. 4).

increase of strength at $4.2 \mathrm{~K}$ in comparison with $350 \mathrm{~K}$ ), indicating that plastic deformation occurs thermally activated. In CG fcc metals and alloys at low temperatures the temperature dependence of flow stress is typically rather weak, and plastic straining is controlled by thermally activated motion of dislocation through the local barriers inside the grains [14], and the typical local barriers are forest dislocations, impurity atoms and clusters, small precipitates, etc. In bcc metals, however, the thermally activated motion of dislocations in the Peierls potential relief determines the macroscopic strength [21] and gives much higher temperature dependence of flow stress than in fcc metals. The measured temperature dependence of strength in CG CoCrFeNiMn is in the middle of fcc and bcc cases, which suggests to apply also the Peierls potential model to this fcc alloy. It is interesting to note that temperature dependences of flow stress for fcc CoCrFeNiMn HEA and for bcc $\mathrm{Ti}_{30} \mathrm{Zr}_{25} \mathrm{Hf}_{15} \mathrm{Nb}_{20} \mathrm{Ta}_{10}$ HEA [22] are rather similar, and as the both models (local barriers and motion in the Peierls potential relief) successfully were applied for approximation of the experimental data for the bcc HEA alloy [22], it can be considered as additional argument for trying the Peierls potential model for the fcc CoCrFeNiMn alloy.

The microscopic plasticity mechanisms of the NC materials with the grain sizes below $100 \mathrm{~nm}$ have not been fully clarified yet, but it has been reported [23,24] that for grain sizes above approximately $20 \mathrm{~nm}$ the plasticity is realized by dislocation motion. Similar temperature dependences of the flow stress and strain rate sensitivities in NC and CG states (Figs. 2, 3) suggest that in NC state these temperature dependences are also related to the thermally activated motion of dislocations, which allows to apply the thermally activation analysis to the experimental data of NC CoCrFeNiMn (Figs. 2-4), results of it will be discussed.

Description of the thermally activated process of plastic deformation in the framework of the transition state theory $[14,25]$ allows relate the plastic strain rate $\dot{\varepsilon}$, activation enthalpy $H$ and temperature $T$ by the Arrhenius-type expression:

$$
\dot{\varepsilon}=\dot{\varepsilon}_{0} \exp \left[-\frac{H\left(\tau^{*}\right)}{k T}\right]
$$

where the pre-exponential factor $\dot{\varepsilon}_{0}$ is constant to a good approximation, $\tau^{*}=\tau-\tau_{i}$ is thermally activated (effective) component of the flow stress $\tau$, and $\tau_{i}$ is the athermal component arising from internal stresses.

\subsection{Local barriers}

The thermally activated motion of dislocation over the local barriers often is described by two models (two statistics): for sufficiently small values of $\tau^{*}$ (almost straight dislocation line) the Mott-Labusch statistics [26] applies, while for significantly curved dislocation segments the Friedel statistics [27] is to be used. Reasonable correlation of the experimental data (Figs. 2-4) with the theory was achieved only for the Friedel model, which thus will be described here in more detail. The analytical approximation of the activation enthalpy for the Friedel model [27-29] reads as

$$
H\left(\tau^{*}\right)=H_{0}\left[1-\left(\frac{\tau^{*}}{\tau_{c}}\right)^{2 / 3}\right]^{q}, \quad 1 \leq q \leq 2,
$$

Table 1. Empirical values of the parameters for the nanocrystalline structural state

\begin{tabular}{c|c|c|c|c|c|c}
\hline \hline Model & $\tau_{i}, \mathrm{GPa}$ & $\tau_{c}\left(\tau_{p}\right), \mathrm{GPa}$ & $H_{0}\left(2 H_{k}\right), \mathrm{eV}$ & $T_{c}, \mathrm{~K}$ & $A$ & $q$ \\
\hline \hline Local barriers & 0.627 & 0.512 & 0.65 & 384 & 19.51 & 1.4 \\
Peierls (regime 1) & 0.617 & 0.458 & 0.74 & 420 & 20.40 & - \\
\hline \hline
\end{tabular}


where $H_{0}$ is the enthalpy parameter of the dislocationbarrier interaction, $\tau_{c}$ is the critical stress for non-thermally activated motion of dislocation over the barrier, and $q$ is a numerical parameter, which depends on the barrier shape.

Relations (2) and (3) provide expressions (4)-(6) for the experimentally measured characteristics of plasticity, i.e., the flow stress $\tau$, strain rate sensitivity $\Delta \tau / \Delta \ln \dot{\varepsilon}$, and the effective activation volume of plastic deformation $V$ :

$$
\begin{gathered}
\tau(T)=\tau_{i}+\tau_{C}\left[1-\left(\frac{T}{T_{C}}\right)^{1 / q}\right]^{3 / 2}, \\
\left(\frac{\Delta \tau}{\Delta \ln \dot{\varepsilon}}\right)_{T} \approx\left(\frac{\partial \tau}{\partial \ln \dot{\varepsilon}}\right)_{T}=\frac{3 \tau_{C}}{2 q A}\left(\frac{T}{T_{C}}\right)^{1 / q}\left[1-\left(\frac{T}{T_{C}}\right)^{1 / q}\right]^{1 / 2} . \\
V=-\left(\frac{\partial H}{\partial \tau^{*}}\right)_{T}=\frac{2 q H_{0}}{3 \tau_{C}}\left(\frac{T}{T_{C}}\right)^{(q-1) / q}\left[1-\left(\frac{T}{T_{C}}\right)^{1 / q}\right]^{-1 / 2} .
\end{gathered}
$$

Here, the parameter $A=\ln \left(\dot{\varepsilon}_{0} / \dot{\varepsilon}\right)$ should not depend significantly on temperature and stress; above the critical temperature $T_{C}=H_{0} / k A$ the thermal part of the flow stress is negligible. The parameters $\tau_{c}, \tau_{i}$ and $H_{0}$ depend on the shear modulus $G$, and correspondingly depend on temperature as the shear modulus does. Use of relations (4)-(6) in a wide temperature range requires to take into account the temperature dependence of these parameters, but here the investigation is limited by a temperature range around $300 \mathrm{~K}$, so in first approximation the corrections due to the temperature dependence of the shear modulus can be neglected.

The parameter $A$ can be estimated by the relation

$$
A=-T\left(\frac{\Delta \tau}{\Delta \ln \dot{\varepsilon}}\right)_{T}^{-1}\left(\frac{d \tau}{d T}\right)_{\dot{\varepsilon}},
$$

which one receives from expressions (4) and (5) considering $d \tau_{i} / d T<<d \tau / \mathrm{d} T$ [29]. Empirical estimates of the parameter $A$, obtained with relation (7) and the experimental dependences $\tau(T)$ and $\Delta \tau / \Delta \ln \dot{\varepsilon}(T)$ (Figs. 2, 3), are shown in Fig. 5 for the NC and CG structural state. As the parameter $A$ does not depend significantly on temperature, the assumption $\dot{\varepsilon}_{0}=$ const holds, being one of the criteria for the applicability of relations (4)-(6) for describing the process of thermally activated plastic flow.
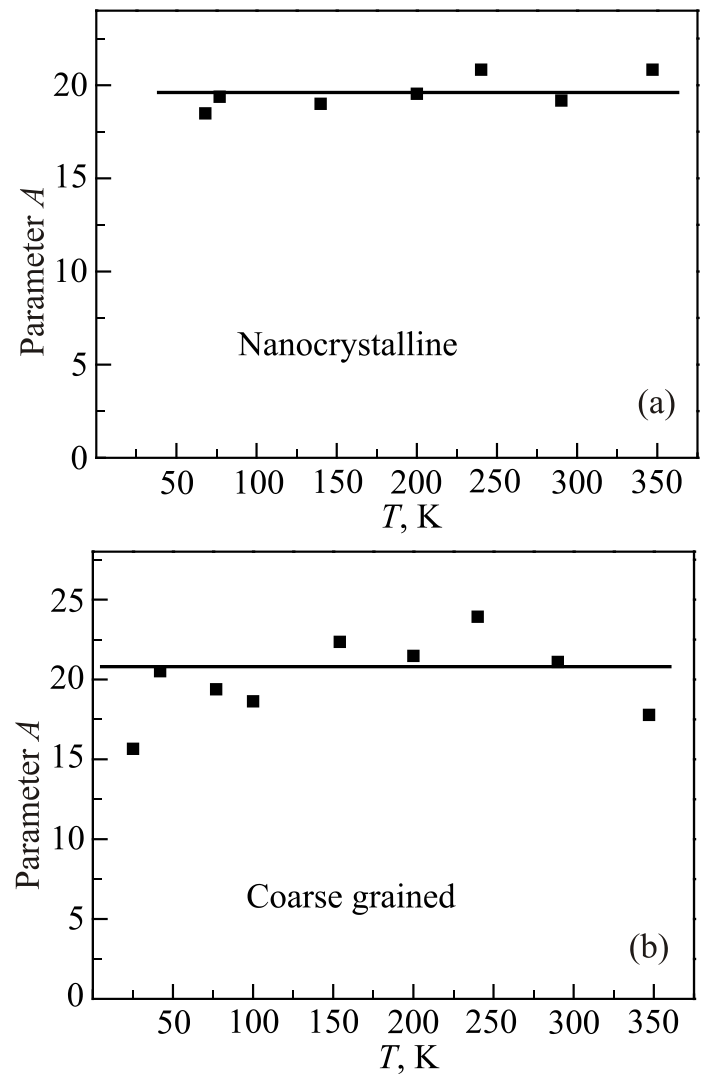

Fig. 5. Temperature dependence of the parameter $A$ in nanocrystalline (a) and coarse grained (b) structural states.

The theoretical equations $\tau(T), \Delta \tau / \Delta \ln \dot{\varepsilon}(T)$ and $V(T)$ (4)-(6) can be fitted to the experimental dependences (Figs. 2-4) to determine material parameters $q, \tau_{i}, \tau_{c}, H_{0}$, $T_{C}, A$ for the model of local barriers. The best fit values of parameters are listed in the first line of Table 1 for NC state and Table 2 - CG state.

The experiments' dependences and approximating theoretical curves (marked as "Local barriers") in Figs. 2-4 show that in the whole temperature range $25 \mathrm{~K} \leq T \leq 350 \mathrm{~K}$ considered for the CG state, and $65 \mathrm{~K} \leq T \leq 350 \mathrm{~K}$ for the NC state, good coincidences of the theoretical and experimental results were achieved, which suggests to consider one single mechanism to control the thermally activated plasticity in the temperature ranges studied.

For the Friedel statistics, the average area $S_{0}$ per local obstacle in the slip plane of a dislocation can be written in the form $[27,30]$.

Table 2. Empirical values of the parameters for the coarse grained structural state

\begin{tabular}{c|c|c|c|c|c|c}
\hline \hline Model & $\tau_{i}, \mathrm{GPa}$ & $\tau_{c}\left(\tau_{p}\right), \mathrm{GPa}$ & $H_{0}\left(2 H_{k}\right), \mathrm{eV}$ & $T_{c}, \mathrm{~K}$ & $A$ & $q$ \\
\hline \hline Local barriers & 0.145 & 0.134 & 0.63 & 353 & 20.80 & 1.71 \\
Peierls (Regime 1) & 0.147 & 0.100 & 0.65 & 365 & 20.76 & \\
Peierls (Regime 2) & 0.143 & 0.110 & 0.54 & 330 & 19.00 & \\
\hline \hline
\end{tabular}




$$
S_{0}=\frac{b^{2} \tau^{*}}{G}\left(\frac{b}{w}\right)^{3}\left(\frac{V}{b^{3}}\right)^{3}
$$

where $G$ is shear modulus, and $w=w\left(\tau^{*}\right)$ is half-width of the barrier for thermal activation.

Using Eq. (8), the values of activation volume (see Fig. 4), and those of the shear modulus of CoCrFeNiMn alloy being $G=80 \mathrm{GPa}$ [31] can be derived. Assuming $w \geq b$, upper estimates of the average area per local obstacle $S_{0}$ can be achieved, being $S_{0 C G} \leq 340 b^{2}$ for the CG state, and $S_{0 N C} \leq 58 b^{2}$ for the NC state; they correspond to the following average distances between the local obstacles in the slip plane: $l_{0 C G}=\left(S_{0 C G}\right)^{1 / 2}<18.4 b=4.7 \mathrm{~nm}$ for CG state, and $l_{0 N C}<7.6 b=1.9 \mathrm{~nm}$ (for NC state).

\subsection{Peierls barriers}

In the frame of this model, the thermally activated motion of dislocations in the Peierls potential relief below the critical temperature $T_{C}$ is realized by nucleation and expansion of kink pairs at the dislocation line [25,32]. Two different regimes of the kink-kink interaction are considered [25,32,33]: in regime 1 at low $\tau^{*}$ values (at high temperatures), the kinks are fully formed and separated, and the enthalpy balance is governed by the elastic interaction between kinks; in regime 2 at high $\tau^{*}$ values (at low temperatures), the dislocation has not reached the adjacent Peierls valley; the kinks have not fully formed yet and can be described by the line tension model.

In the regime 1, the activation enthalpy is represented by the formation of kink pairs, that is, associated with elastic repulsion of the kink pair. This can be quantified according to $[25,34]$ as

$$
\Delta H_{k p}=2 H_{k}\left[1-\left(\frac{\tau^{*}}{\tau_{p}}\right)^{1 / 2}\right]
$$

where $H_{k}$ is the formation enthalpy of the isolated kink, and $\tau_{p}$ is the critical stress of the athermal part of dislocation motion over the Peierls barrier.

Combining equations (2) and (9), expressions for the flow stress $\tau$, strain rate sensitivity $\Delta \tau / \Delta \ln \dot{\varepsilon}$, and the activation volume of plastic deformation $V$ can be obtained as follows:

$$
\begin{gathered}
\tau(T)=\tau_{i}+\tau_{p}\left[1-\frac{T}{T_{c}}\right]^{2} \\
\left(\frac{\Delta \tau}{\Delta \ln \dot{\varepsilon}}\right)_{T} \approx\left(\frac{\partial \tau}{\partial \ln \dot{\varepsilon}}\right)_{T}=\frac{2 \tau_{p}}{A}\left(\frac{T}{T_{c}}\right)\left[1-\frac{T}{T_{c}}\right], \\
V=-\left(\frac{\partial H}{\partial \tau^{*}}\right)_{T}=\frac{H_{k}}{\tau_{p}}\left[1-\frac{T}{T_{c}}\right]^{-1} .
\end{gathered}
$$

Where $A=\ln \left(\dot{\varepsilon}_{0} / \dot{\varepsilon}\right)$, and $T_{C}=2 H_{k} / k A$.
Joint approximation of the experimental data (Figs. 2-4) by the relations (10)-(12) allows to self-consistently find the values of all theoretical parameters $\tau_{i}, \tau_{p}, H_{k}, T_{c}$, A, which are given in line 2 of Tables 1 and 2 for the NC and CG state correspondingly. Note that the approximated value of parameter $A$ coincides well with its empirical value calculated by Eq. (7) (also shown in Fig. 5), which is an additional prove of the consistency of the model. The Regime 1 of the thermally activated flow typically is valid at relatively low stresses $\tau^{*}<\tau_{p} / 2$ [32], and correspondingly the relations (10)-(12) should correlate with the experimental data at not too low temperatures (e.g., above 100-150 K). However, it can be seen from Figs. 2-4 that even in the whole range of low temperatures studied, the theoretical curves (10)-(12) of the regime 1 of the Peierls model (noted as "Peierls, Regime 1" at Figs. 2-4) are in good correlation with the experimental data.

At high values of $\tau^{*}$ (at low temperatures) the line tension approximation of the kink interaction (Regime 2) gives the activation enthalpy $[25,34]$ in the form

$$
\Delta H_{k p}=2 H_{k} \frac{6}{5}\left[\frac{2}{3}\left(1-\frac{\tau^{*}}{\tau_{p}}\right)\right]^{5 / 4}
$$

where $H_{k}$ is formation enthalpy of the isolated kink, and $\tau_{p}$ is the critical stress of the non-activated motion of dislocation over the Peierls barrier.

Now, the temperature dependences of the flow stress $\tau$, strain rate sensitivity $\Delta \tau / \Delta \ln \dot{\varepsilon}$, and the activation volume of plastic deformation $V$ can be obtained also for the regime 2, with the use of (2) and (13):

$$
\begin{gathered}
\tau(T)=\tau_{i}+\tau_{p}\left[1-\frac{3}{2}\left(\frac{5}{6} \frac{T}{T_{c}}\right)^{4 / 5}\right], \\
\left(\frac{\Delta \tau}{\Delta \ln \dot{\varepsilon}}\right)_{T} \approx\left(\frac{\partial \tau}{\partial \ln \dot{\varepsilon}}\right)_{T}=\frac{\tau_{p}}{A} \frac{6}{5}\left(\frac{5}{6} \frac{T}{T_{c}}\right)^{4 / 5}, \\
V=-\left(\frac{\partial H}{\partial \tau^{*}}\right)_{T}=\frac{2 H_{k}}{\tau_{p}}\left(\frac{5}{6} \frac{T}{T_{c}}\right)^{1 / 5},
\end{gathered}
$$

where $A=\ln \left(\dot{\varepsilon}_{0} / \dot{\varepsilon}\right)$, and $T_{C}=2 H_{k} / k A$.

Approximation of $\tau(T)$ and $\Delta \tau / \Delta \ln \dot{\varepsilon}(T)$ (Figs. 2(b), 3(b)) by the relations (14) and (15) for the CG alloy gives empirical values of the parameters $\tau_{i}, \tau_{p}, H_{k}, T_{c}$, A (line 3 of the Table 2). It can be seen from Figs. 2(b) and 3(b) that the low temperature model of the Regime 2 is valid at temperatures below $100-150 \mathrm{~K}$, and that at higher temperatures the elastic approximation of regime 1 more adequately corresponds to experimental data. For the NC alloy, the low plasticity below $65 \mathrm{~K}$ did not allow to measure the strain rate sensitivity, and correspondingly there are not sufficient experimental points to perform approximations for the low temperature regime 2 as well. 


\subsection{Discussion of the thermally activated plastic deformation}

As the thermally activated motion of dislocations over the local barriers inside the grains is the main microscopic plasticity mechanism of the CG CoCrFeNiMn high entropy alloy, the knowledge on microscopic parameters of the thermal activation analysis (Table 2) could help to identify the type of barriers. Considering forest dislocations as the possible local barriers - taking into account that the area per local obstacle is $S_{0 C G} \leq 340 b^{2}$ - an estimation of the required dislocation density gives $1 / S_{0 C G} \geq 4.5 \cdot 10^{16} \mathrm{~m}^{-2}$, which is too high for CG not severely deformed material. Impurity atoms also cannot be these local barriers, because the alloy doesn't contain the impurity, whose concentration would provide the estimated distance between the barriers $4.5 \mathrm{~nm}$. Alloy atoms also cannot represent these local barriers, because the alloy concentration is much too high to provide the estimated barrier distance of $4.5 \mathrm{~nm}$. However, several neighboring atoms of the present HEA alloy with relatively high atomic radius can cause distinctly increased lattice distortions, and therefore may act as the barriers for the dislocation motion. Indeed, such "clusters" of atoms were experimentally observed in high entropy alloys [35], with a typical distance between them of several nanometers; this value equals that from the estimation done by the thermally activation analysis by means of the local barrier model. Moreover, the value of activation energy $0.63 \mathrm{eV}$ (Table 2) obtained from this model is more typical of a complex local obstacle than of a single impurity atom; altogether an interpretation of plasticity process with the thermally activated overcome of complex atom clusters seems to be rather convenient. Unfortunately, at the moment no detailed statistics is available of the clusters sizes and distribution, which not allows more exact analysis.

Alternatively, motion of dislocation in grains of CG CoCrFeNiMn can be controlled by thermally activated overcoming by dislocations of the Peierls potential relief - the model demonstrates good correlation with the experimental results (Figs. 2-4). The activation energy (energy of the kink pair formation) for the low and high temperature regimes of the Peierls barrier model of CoCrFeNiMn (Table 2) $(0.54 \mathrm{eV}$ and $0.65 \mathrm{eV}$ ) are in reasonable correlation with the kink pair formation energy of the metals (elements of the alloy), whose dislocation motion is controlled by the Peierls barriers: Fe $0.58 \mathrm{eV}, \mathrm{Cr}-0.93 \mathrm{eV}$ [21]. Modelling of the single crystal CoCrFeNiMn alloy utilizing the Peierls-Nabarro formalism by density functional theory calculations [20] gives estimation of the Peierls stress: $178 \mathrm{MPa}$. This estimate is in rather good agreement with the values of the Peierls stress from the thermal activation analysis (Table 2) $100 \mathrm{MPa}$ and $110 \mathrm{MPa}$ for the Regimes 1 and 2 correspondently.

Such agreement of the thermal activation analysis with estimate of the Peierls stress from the single crystal modeling and good correlation of the Peierls model with the experi- mental results (Figs. 2-4) allow to consider at the moment the thermally activated overcoming by dislocations of the Peierls potential relief as the most probable microscopic mechanism, which control the motion of dislocations in grains of the CG CoCrFeNiMn alloy. However, when microscopic parameters of dislocation interaction with the local clusters as well as a statistics of the cluster's distribution will be available, the additional comparison of the models will be required. It also should be noted that both models (local clusters and Peierls barriers) give very similar values of the microscopic parameters of the dislocation-barrier interaction (Table 2), which indicate that maybe both of them are relevant and they describe the same effect from different sides, for example the size of the kink pair can be influenced by variation of local composition of atoms (a sort of clusters along the Peierls valley). The recently developed model for solute strengthening of random FCC alloys [36] could be such an alternative to the models of the local barriers and the Peierls barriers, but the attempt to apply this solute strengthening model to the thermally activated plastic deformation of the CG CoCrFeNiMn [10] has shown that the predictions of the model are not able at the moment correlate to experimental results sufficiently good (for example, values of the activation volume from theory and experiment differed several times), so the model should be improved to use it for describing the thermally activated plastic deformation of the high entropy alloys.

Concerning the relevance of the Peierls relief model in NC state of the CoCrFeNiMn high entropy alloy, the thermal activation analysis gives the value of the Peierls stress of $458 \mathrm{MPa}$ (Table 1), which is much higher than in CG state, although the height of the Peierls barrier should not depend on grain size. And like in case of CG state, this value is much higher than that estimated from the single crystal modelling [20], meaning that thermally activated motions of dislocations over the Peierls barriers inside the grains cannot control the plastic deformation. On the other hand, for the NC state the estimation of the distance between the local clusters to be $7 b$ by means of the barrier model looks too small: it is difficult to imagine the two clusters with a curved dislocation segment between them at the area of seven interatomic distances. Moreover, this result would mean that the distance between the clusters in the NC state is much smaller than in CG state, which has no relevant explanation. Alternatively, the commonly accepted viewpoint in literature [24] is that in NC materilas the process of plastic deformation is not controlled by motion of dislocations inside the grains, but by the nucleation of dislocations at the grain boundaries. As these dependences of the flow stress, strain rate sensitivity and activation volume of the NC CoCrFeNiMn are very similar to that of the CG state, this indicates similar processes to occur, but with much higher barriers for the thermally activated plastic deformation. Indeed, such high barriers may be represented by the grain boundaries of the NC state. Then the model of local barriers 
probably concerns the dislocation line, which had been already nucleated at the grain boundary, but pinned there at several points (probably at ledges). Under applying stress, these dislocation segments will bow out, and the plastic deformation is controlled by thermally activated tearing-off the bowed dislocation segment from the pinning ledges within the grain boundary, followed by subsequent free motion of dislocation through the grain. During the latter, the local barrier model (Table 1) gives the stresses and energy parameters of thermally activated transition of dislocation to the grain as well as the estimate of average distance between the ledges at the grain boundary. As well as the model of Peierls barrier can describe the transition of dislocation from grain boundary to the neighboring Peierls valley and Table 1 gives the microscopic parameters of this process. The computer simulations of the NC materials [24] confirm the possibility of dislocation nucleation at grain boundaries.

\section{Conclusions}

The process of plastic deformation of the NC and CG CoCrFeNiMn high entropy alloy has been studied in a wide range of low temperatures. NC CoCrFeNiMn demonstrates exceptionally high strength (especially for fcc material), which achieves $3 \mathrm{GPa}$ at $4.2 \mathrm{~K}$, while maintaining reasonable plasticity even at cryogenic temperatures. The yield stress and strain rate sensitivity of flow stress have been registered at temperatures 4.2-345 K. Values of the activation volume of the process of plastic deformation have been evaluated from the strain rate sensitivity. Experimentally measured temperature dependences of the flow stress and strain rate sensitivity in a wide range of low temperatures indicate thermally activated plasticity of both the CG and the NC CoCrFeNiMn high entropy alloy. Thermal activation analysis for the CG CoCrFeNiMn has shown that plastic deformation most probably is controlled by thermally activated motion of dislocation in grains over the Peierls potential relief. The thermally activated process in the nanocrystalline material can be interpreted as the generation of dislocation from grain boundary and the transition to the grain interior. Microscopic parameters of dislocation interaction with the barriers for thermally activated motion are estimated for CG and NC structural states of the CoCrFeNiMn high entropy alloy.

The authors have pleasure to dedicate this publication to the 80th anniversary of Prof. V.D. Natsik and express gratitude for interest to the work and useful discussions.

1. W. Yeh, S.K. Chen, S.J. Lin, J.Y. Gan, T.S. Chin, T.T. Shun, C.H. Tsau, and S.Y. Chang, Adv. Eng. Mater. 6, 299 (2004).

2. B. Cantor, I.T.H. Chang, P. Knight, and A.J.B. Vincent, Mater. Sci. Eng. A 375, 213 (2004).

3. B. Gludovatz, A. Hohenwarter, D. Catoor, E.H. Chang, E.P. George, and R.O. Ritchie, Science 345, 1153 (2014).
4. Y. Zhang, T.T. Zuo, Z. Tang, M.C. Gao, K.A. Dahmen, P.K. Liaw, and Z.P. Lu, Progr. Mater. Sci. 61, 1 (2014).

5. A. Gali and E.P. George, Intermetallics 39, 74 (2013).

6. F. Otto, A. Dlouhy, Ch. Somsen, H. Bei, G. Eggeler, and E.P. George, Acta Mater. 61, 5743 (2013).

7. E.D. Tabachnikova, A.V. Podolskiy, M.O. Laktionova, N.A. Bereznaia, M.A. Tikhonovsky, and A.S. Tortika, J. Alloys Comp. 698, 501 (2017).

8. Z. Wu, Y. Gao, and H. Bei, Acta Mater. 120, 108 (2016).

9. S.I. Hong, J. Moon, S.K. Hong, and H.S. Kim, Mater. Sci. Eng. A 682, 569 (2017).

10. G. Laplanche, J. Bonneville, C. Varvenne, W.A. Curtin, and E.P. George, Acta Mater. 143, 257 (2018).

11. B. Schuh, F. Mendez-Martin, B. Völker, E.P. George, H. Clemens, R. Pippan, and A. Hohenwarter, Acta Mater. 96, 258 (2015).

12. A.V. Podolskiy, E.D. Tabachnikova, S. Maier, M.J. Zehetbauer, C. Rentenberger, B. Joni, M.A. Tikhonovsky, A. Tortika, and E. Schafler, Mater. Design (2018), in submission.

13. J.P. Hirth and J. Lothe, Theory of Dislocations, McGrawHill, New York (1968).

14. A. Evans and R. Rawlings, Phys. Status Solidi 34, 9 (1969).

15. V.V. Pustovalov, Fiz. Nizk. Temp. 34, 871 (2008) [Low Temp. Phys. 34, 683 (2008)].

16. N.D. Stepanov, D.G. Shaysultanov, G.A. Salishchev, M.A. Tikhonovsky, E.E. Oleynik, A.S. Tortika, and O.N. Senkov, J. Alloys Comp. 628, 170 (2015).

17. E.D. Tabachnikova, A.V. Podolskiy, S.N. Smirnov, I.A. Psaruk, V.Z. Bengus, H. Li, L. Li, H. Chu, and P.K. Liao, Fiz. Nizk. Temp. 380, 301 (2012) [Low Temp. Phys. 38, 239 (2012)].

18. G. Laplanche, A. Kostka, O.M. Horst, G. Eggeler, and E.P. George, Acta Mater. 118, 152 (2016).

19. N. Stepanov, M. Tikhonovsky, N. Yurchenko, D. Zyabkin, M. Klimova, S. Zherebtsov, A. Efimov, and G. Salishchev, Intermetallics 59, 8 (2015).

20. L. Patriarca A. Ojha, H. Sehitoglu, and Y.I. Chumlyakov, Scripta Mater. 112, 54 (2016).

21. H. Conrad and W. Hayes, Amer. Soc. Metals 56, 249 (1963).

22. A.V. Podolskiy, E.D. Tabachnikova, V.V. Voloschuk, V.F. Gorban, and S.A. Firstov, Mat. Sci. Eng. A 710, 136 (2018).

23. H. Li, F. Ebrahimi, H. Choo, and P.K. Liaw, J. Mater. Sci. 41, 7636 (2006).

24. M.A. Meyers, A. Mishra, and D.J. Benson, Progr. Mater. Sci. 51, 427 (2006).

25. A. Seeger, Z. Metallk. 72, 369 (1981).

26. B. Schwarz and R. Labusch, J. Appl. Phys. 49, 5174 (1978).

27. J. Friedel, Dislocations, London, Pergamon (1964).

28. U.F. Kocks, A.S. Argon, and M.F. Ashby, Progr. Mater. Sci. 19, 1 (1975).

29. V.N. Kovaleva, V.A. Moskalenko, and V.D. Natsik, Philos. Mag. A 70, 423 (1994).

30. E.D. Tabachnikova, A.V. Podolskiy, S.N. Smirnov, I.A. Psaruk, and P.K. Liao, Fiz. Nizk. Temp. 40, 1419 (2014) [Low Temp. Phys. 40, 1104 (2014)]. 
31. B. Gludovatz, E.P. George, and R.O. Ritchie, JOM 67, 2262 (2015).

32. A. Seeger, Mater. Sci. Eng. A 370, 50 (2004).

33. H. Lim, C.C. Battaile, J.D. Carroll, B.L. Boyce, and C.R. Weinberger, J. Mech. Phys. Sol. 74, 80 (2015).

34. A. Seeger, J. Phys. Colloq. 42(C5), 201 (1981).

35. E.J. Pickering, H.J. Stone, and N.G. Jones, Mater. Sci. Eng. A 645, 65 (2015).

36. G. Leyson, L. Hector, and W. Curtin, Acta Mater. 60, 3873 (2012).

Термоактивована деформація нанокристалічного та крупнозернистого високоентропійного сплаву CoCrFeNiMn у діапазоні температур 4,2-350 К

\section{А.В. Подольський, Е. Шафлер, О.Д. Табачнікова, М.A. Тихоновський, М.J. Zehetbauer}

Механічні властивості нанокристалічного (середній розмір зерен $\sim 60$ нм) та крупнозернистого (середній розмір зерен $\sim 4$ мкм) високоентропійного сплаву CoCrFeNiMn вивчались шляхом одноосного стискання в інтервалі температур 4,2-350 К. Температурна залежність межі плинності, напруження течії та швидкісної чутливості деформуючого напруження виміряно та проаналізовано в рамках двох термоактиваційних моделей: моделі взаємодії дислокацій 3 локальними бар'єрами та моделі Пайєрлса щодо утворення подвійних перегинів. Визначено мікроскопічні параметри взаємодії дислокацій 3 бар'єрами при термоактивованому русі та обговорюються низькотемпературні механізми, які контролюють пластичну деформацію.

Ключові слова: високоентропійні сплави, нанокристалічні метали, низькі температури, дислокації, термоактиваційний аналіз.

\section{Термоактивированная десормация нанокристаллического и крупнозернистого высокоэнтропийного сплава CoCrFeNiMn в диапазоне температур 4,2-350 K}

\section{А.В. Подольский, Е. Шафоер, Е.Д. Табачникова, М.A. Тихоновский, М.J. Zehetbauer}

Механические свойства нанокристаллического (средний размер зерен $\sim 60$ нм) и крупнозернистого (средний размер зерен $\sim 4$ мкм) высокоэнтропийного сплава $\mathrm{CoCrFeNiMn}$ изучались путем одноосного сжатия в интервале температур 4,2-350 К. Температурная зависимость предела текучести, напряжения течения и скоростной чувствительности деформирующего напряжения измерены и проанализированы в рамках двух термоактивационных моделей: модели взаимодействия дислокаций с локальными барьерами и модели Пайерлса образования двойных перегибов. Определены микроскопические параметры взаимодействия дислокаций с барьерами при термоактивированном движении и обсуждаются низкотемпературные механизмы, которые контролируют пластическую деформацию.

Ключевые слова: высокоэнтропийные сплавы, нанокристаллические металлы, низкие температуры, дислокации, термоактивационный анализ. 